\section{LATE BRONZE AGE STRUCTURE AND EARLIER FEATURES (AREA H)}

Area $\mathrm{H}$ was located on the top of a knoll to the west of the development area. Discovered in this area (Illus 39) were the remains of an adult cremation burial, the remains of a probable post-built circular structure largely defined by a section of ring groove, and a scatter of 175 pits, some of which contained calcined bone and pottery, and one of which contained a fragment of a cannel coal bracelet.

There was also a discontinuous linear feature, orientated north-west/south-east, which bisected the site in its southern portion. To the south-west of this, two concentrations of features were noted (Areas 1 and 2), which are the probable remains of heavily truncated structures. The putative structures were defined by large pits interpreted as the remains of ring ditches, and sections of ring grooves. It is possible to discern other curving lines and small groups of post holes amongst the distributions across this area, but none is convincing enough to describe in detail.

\subsection{Structure $1 \mathrm{H}$}

\subsubsection{General summary}

A very truncated and ill-defined circular structure was identified in this area (Illus 39). It was initially recognised from the remnants of a ring groove on its south-west quadrant. It was post-built, with a diameter of $c 11 \mathrm{~m}$. A number of internal features were also identified.

\subsubsection{Description}

The features defining this structure were largely sealed by a black to dark brown charcoal-rich deposit of silt (659) $c 4 \mathrm{~m}$ by $5 \mathrm{~m}$ by $0.04 \mathrm{~m}$ deep, possibly representing a destruction layer. The structure was

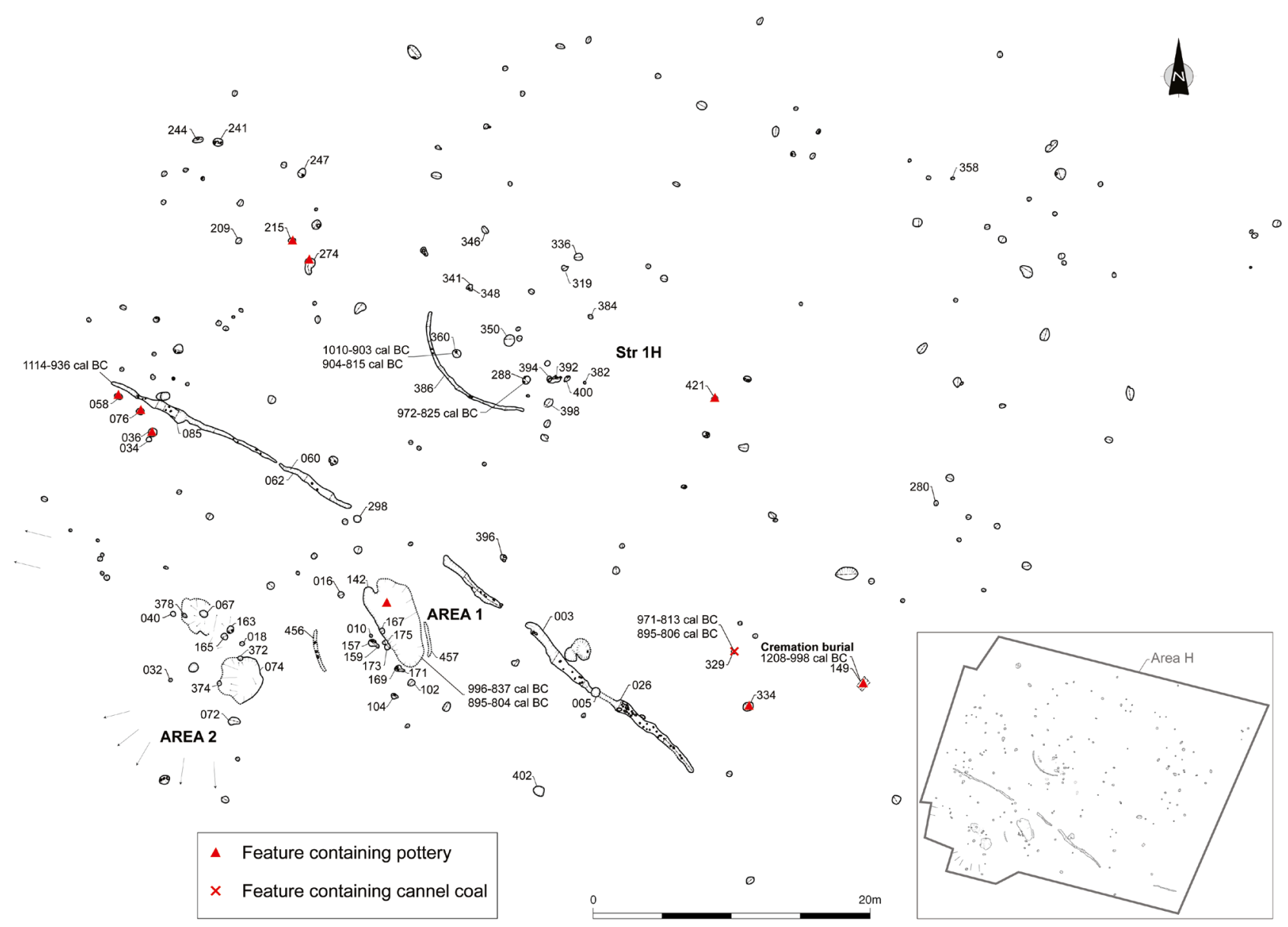


defined by the remnants of a ring groove to the south-west, 386 , measuring $12 \mathrm{~m}$ by $0.2-0.3 \mathrm{~m}$ wide by $0.1 \mathrm{~m}$ deep, and by pits that lay on the projected path of the ring groove, two to the south-east (398 and 382) and two to the north (346 and 336). There were 18 sub-circular pits recorded within the putative internal space of the structure. The pits were heavily truncated and ranged in size from $0.4 \mathrm{~m}$ diameter by $0.19 \mathrm{~m}$ deep to $0.65 \mathrm{~m}$ by $0.6 \mathrm{~m}$ by $0.28 \mathrm{~m}$ deep.

What may be the partial remains of a post ring were defined by eight post holes (392/394, 288, 360, $341 / 348,319,384$ and 400), one of which (360) contained packing stones. Charcoal from Features 288 and 360 returned LBA date ranges (Table 14). The proximity of Post Holes 392 and 394 is indicative of a replacement post, but unfortunately a large stone sat in the interface been the two cuts, blurring the stratigraphic relationship between them. The stone was probably packing material within the post holes. It is difficult to assign a function to the other six internal pits as there was no recognisable spatial patterning or architectural arrangement. The function of Pit 350 is difficult to determine but its profile suggests that it once contained a post that had been removed by pulling or pushing to the west. There was no obvious entrance into the structure.

\subsubsection{Interpretation and phasing}

The structure has architectural elements found in other structures at Blackford, including a ring groove and a single post ring, both only partially surviving. There is scant evidence to suggest anything other than a single-phase building, and although there is

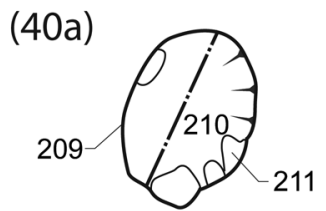

(40d)

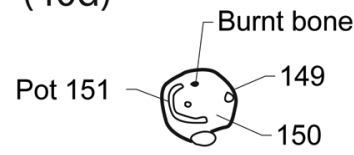

(40b)

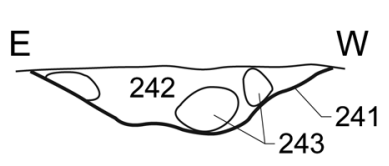

(40e)

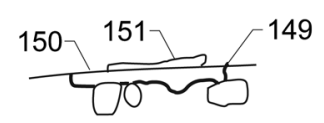

(40c)

300

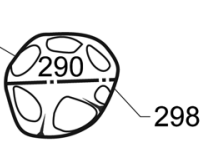

(40f)

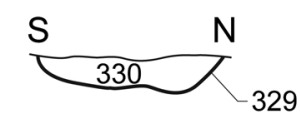

(40g)

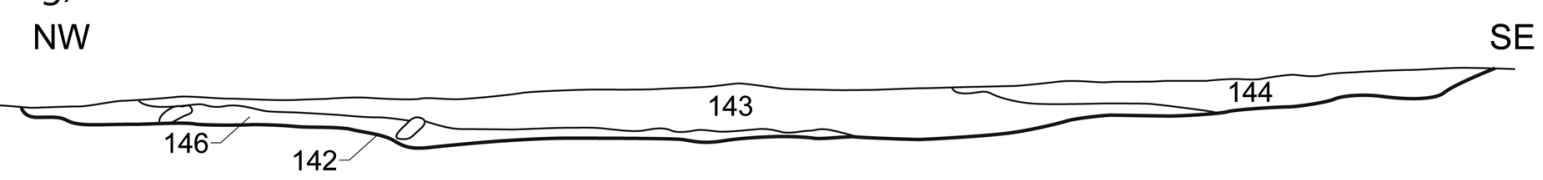

(40h)

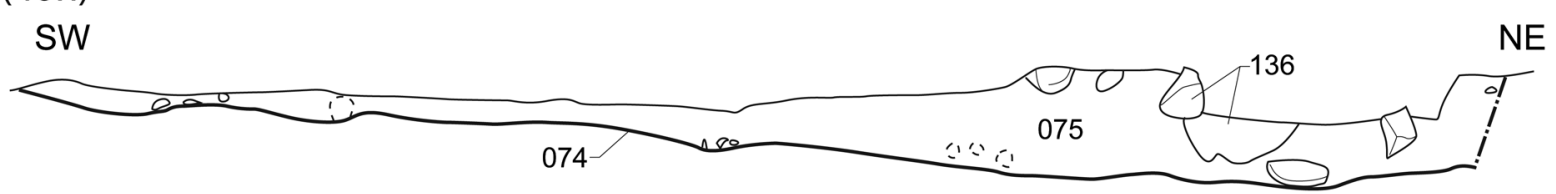

(40i)
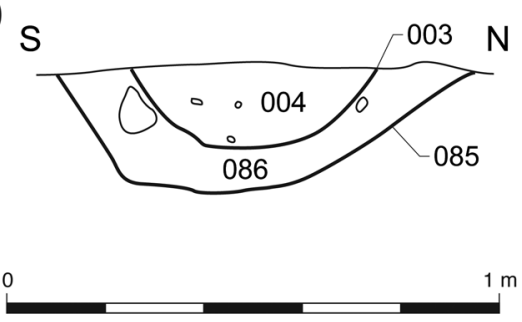

Illus 40 Selected sections of isolated pits, Areas 1 and 2, and Gully 003, Area H 
some evidence for a post replacement, this is likely to have happened during the building's occupation. The radiocarbon dates from Pit 360 are inconsistent, but the majority of samples from both 360 and 288 return LBA dates.

\subsection{Scatter of pits}

In total there were 175 pits, excluding those associated with Structure $1 \mathrm{H}$. Ten of these pits were identified as possible post holes as they had stone packing material within them (examples shown in Illus $40 \mathrm{a}-\mathrm{c}$ ), four of which were grouped to the north-west of the site $(209,241,247$ and 244), five within the south-west quadrant of the site (036, 067, 298, 396 and 402) and one within the north-east quadrant of the site (358). The function of the remaining 165 pits could not be determined, but broad curving patterns can be seen, which may indicate heavily truncated post rings.

Pit 149 (Illus 40d \& e) contained the heavily truncated remains of a cremation urn containing burnt bone fragments identified as an adult (Section 7.6 below) which returned a radiocarbon date range of 1209-998 cal вС (95\% probability; UBA-13439). Pit 329 (Illus 40f), $c 5 \mathrm{~m}$ to the west of 149 , contained a fragment of cannel coal bangle (see Section 7.5.2) and a small quantity of burnt bone of indeterminate species (see Section 7.7.1).

\subsection{Areas 1 and 2}

These two areas were of interest because of the concentration of small pits adjacent to two large pits (142 and 074), a possible occupation or destruction layer and the vestigial remains of a curvilinear gully.

Area 1 included a large curvilinear pit (142), reminiscent in size and form to a truncated ring ditch (Illus 40g), and 11 smaller pits clustered around its southern and western sides $(010,016$, 102, 104, 157, 159, 167, 169, 171, 173 and 175). Two sections of curvilinear gullies (456 and 457) were recorded on the west and east sides of Pit 142.

The features of Area 2, which were sealed by a deposit of black to dark brown sandy silt (066), included a large pit (074 Illus 40h) and 10 smaller pits $(018,032,038,040,072,163,165,372,374$ and 378). There was some evidence that 074 was stone-lined.

\subsection{Linear feature}

A discontinuous linear feature (003) bisected the site on a north-west/south-east axis. The feature was irregular both in its dimensions and its profile. It was heavily truncated, surviving in places as little more than a stain. At its north-western extremity the feature could be seen to run down the slope for a short section before it became untraceable, while at its south-east extremity it also tapered out and was not seen in the evaluation trenches to the south and east. There were four breaks along its length, but it could not be established whether they were by design or as a result of truncation.

The feature cut Pit 085 (Illus 40j) on its north-east arm and was cut by 005 on its middle section. Three other pits were identified within the linear feature (060, 062 and 026), seen in section only.

The feature may have been part of a bigger enclosing feature such as a palisade, the rest of which has been truncated. It may equally have been a linear boundary, possibly fabricated from timber, based on the evidence of the three probable post holes within the feature. Alternatively it may have been a hedge line, which could explain its irregularity and undulating base, interpreted in the field as possible root boles. No field boundaries are depicted in this area on the early Ordnance Survey maps, suggesting that if it is a field boundary it was not identifiable as such when these maps were drawn up.

\subsection{Artefacts}

\subsubsection{Pottery}

Melanie Johnson

An assemblage of 92 sherds was recovered from this area, comprising a scatter of sherds from some of the many pits spread across this area, and a single urned cremation deposit.

A cluster of four pits on the west side of the excavation area contained a small quantity of pottery (10 sherds). Pits 034 and 076 each contained a rim sherd (P162 and P166 respectively, Illus 41). Both of these were rounded rims from neutral-mouthed bowls. The former has a diameter of $180 \mathrm{~mm}$. Plain body sherds were found in the adjacent Pits 036 and 058.

Further plain body sherds were also found in adjacent Pits 215 and 274, in Pit 334 and during 
general site cleaning. A rim (P174) was also found in Pit 421, slightly to the east of Structure $1 \mathrm{H}$. This small sherd was a tapered rim, bevelled to each side; little of the profile survived (Illus 41).

The possible structure referred to as Area 1 includes a large pit (142) which contained three plain body sherds.

There were no significant differences between the fabrics recorded across the site, with generally coarse, sometimes sandy fabrics containing varying quantities of grit and small stones, and probably of MBA/LBA date.

The majority of the pottery was from Pit 149 , a small oval pit in the south-east of the area, where the vessel (P176 Illus 41) comprised in-situ base and body sherds weighing $1,270 \mathrm{~g}$. The vessel was removed in a block of soil for excavation in the laboratory due to the presence of cremated human bone. Plough damage had removed the upper portion of the vessel, to such an extent that the overall morphology of the vessel is unknown. Almost the whole of the base is present, with about three-fifths of the circumference of the wall to a height of $10 \mathrm{~mm}$. The base diameter is $140 \mathrm{~mm}$ with a wall thickness of $15 \mathrm{~mm}$. The fabric is coarse and heavily gritted, with a pink to orange interior, grey core and orange exterior. The surfaces are smoothed and there is sooting on the interior. This vessel is the remains of an upright urned cremation, containing the cremated remains of an adult (see Section 7.6).

Fragments of potentially two other vessels were recorded in the fill of Pit 149 . Five small plain body

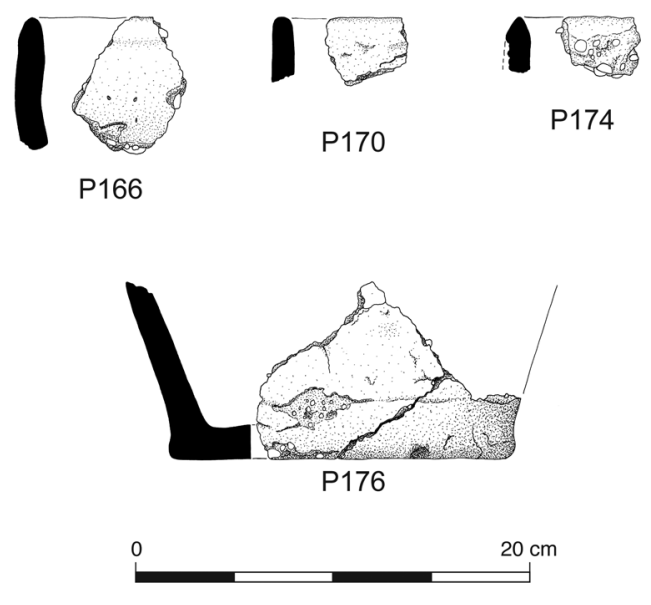

Illus 41 Pottery from Area H sherds which differed in colour and fabric to the urn P176 were found, and two rim sherds from a vessel with a rounded rim and slight internal bevel (P170 Illus 41). This rim had a diameter of $220 \mathrm{~mm}$ and again differed in colour and fabric from urn P176. However, given that only the base of P176 survived intact, and it is not uncommon for the base of a vessel to be thicker and more heavily gritted than the rim portion, it remains a possibility that these additional sherds belonged to the upper portion of the cremation urn and it is due to construction techniques and firing conditions that they appear superficially to be from different vessels.

\subsubsection{Cannel coal bangle \\ Fraser Hunter}

A bangle fragment was recovered from Pit 329, to the west of the cremation burial. Bangles are common later prehistoric finds, and are not chronologically diagnostic; evidence of use-wear shows this one had an extended life.

\section{Catalogue (Illus 42)}

- Bangle fragment, split horizontally and broken at ends. The surviving fragment comes from the top of a fairly broad D-sectioned bangle, rounded internally. There are near-vertical abrasion scars on the inner face, polished from wear; the exterior is well-finished but has considerable use-wear
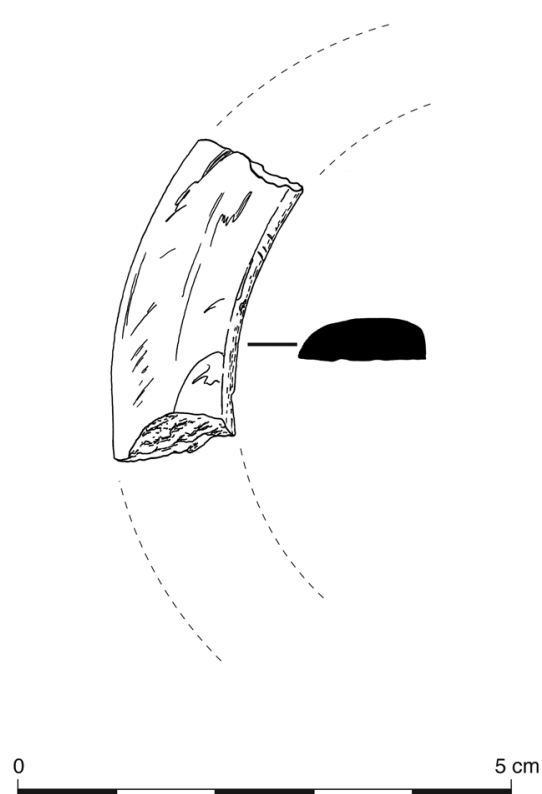

Illus 42 Cannel coal bangle from Area $\mathrm{H}$ 
scratching, and a small spall has worn smooth from use. The conchoidal fracture suggests it is probably cannel coal. L 34, W 12.5, T $6.5 \mathrm{~mm}$; internal D $75-80 \mathrm{~mm}$ (12\% survives). Pit 329.

\subsection{Cremated human remains}

\section{Sue Anderson}

Pit 149 was the heavily truncated remains of an urned cremation burial. Some of the fill was recovered as a sample on site $(<714>)$, and the remainder was lifted as a block containing the base of the pot and some of the pit fill. This was excavated in the laboratory, providing Samples $<1134>$ (Pit Fill 150) and <1135> (Pit Fill 151). These were sieved for the recovery of bone and other organic material. The shallow nature of the pot base meant that excavation of the urn in spits was not feasible. The residues from wet-sieving were dried, sieved into three fractions $(<2 \mathrm{~mm},>2 \mathrm{~mm},>4 \mathrm{~mm})$ and were then sorted into areas of the skeleton. The results for each sample are shown in Table 13 (the quantification by fraction is included in the archive). The total bone weight was $45.1 \mathrm{~g}$, and in addition ten fragments $(1 \mathrm{~g})$ of bone from the urn were identified as possibly animal.

Fragments recovered both from the inside of the urn and the soil surrounding it were small, and abraded pieces occurred in both. There was no reason to suppose the fragments from the outside of the urn were from a different individual to those contained within, and it is likely that plough damage had resulted in some displacement of the urn's contents. The largest fragment sizes of skull and long bone were $16 \mathrm{~mm}$ and $28 \mathrm{~mm}$ respectively from within the urn, and $7 \mathrm{~mm}$ and $10 \mathrm{~mm}$ from the pit fill.
The individual was an adult, based on the size of the long bones and the completeness of the few surviving tooth roots. No elements diagnostic for sexing or closer ageing were present. The remains were too fragmentary to provide any further information about the individual buried here.

\subsection{Environmental evidence}

\subsubsection{Calcined bone}

\section{Sue Anderson}

Calcined animal and uncertain bone was recovered from Structure $1 \mathrm{H}(10.35 \mathrm{~g})$, Area $1(4.4 \mathrm{~g})$, Area 2 $(0.1 \mathrm{~g})$ and 25 other features $(32.35 \mathrm{~g})$ on this site. The largest single quantities were from Pits 076 (5.2g), 215 (4.3g) and 329 (7.2g). Fragments from 076 included pieces of tooth root and mandible which could possibly be human, although there were certainly animal fragments present in the context too; a small quantity of pottery was also recovered from this feature (see Section 7.5.1).

\subsubsection{Charcoal Michael Cressey}

Eight samples of charcoal were analysed from this area. Both hazel (25 identifications, 14g) and oak (165 identifications, 38.1g) are present, with oak dominating at $73 \%$ of the assemblage.

\subsubsection{Charred plant remains}

Mhairi Hastie

\section{Composition of plant remains}

A mixture of naked barley, emmer and spelt wheat was recovered from this area. Cereal grains were present, along with small amounts of wild taxa such as sedge, buttercup and hemp nettle. Fragments of hazelnut shell were present in the fill of only one

Table 13 Cremation burial quantification

\begin{tabular}{lrrrrrrrrrrrr} 
Sample & Skull & & \multicolumn{1}{c}{ Axial } & & \multicolumn{2}{c}{ Upper limb } & Lower limb & \multicolumn{2}{c}{$\begin{array}{l}\text { Unident. } \\
\text { limb }\end{array}$} & Unident. \\
& No. & Wt $(\mathrm{g})$ & No. & Wt $(\mathrm{g})$ & No. & Wt $(\mathrm{g})$ & No. & Wt $(\mathrm{g})$ & No. & Wt $(\mathrm{g})$ & Wt $(\mathrm{g})$ \\
\hline 714 & & & & & & & & & & & 1.4 \\
\hline 1134 & 2 & 0.1 & & & & & & & 5 & 0.8 & 1.9 \\
\hline 1135 & 35 & 3.6 & & & 7 & 2.4 & 20 & 4.9 & 27 & 5.8 & 24.2 \\
\hline Totals & 37 & 3.7 & 0 & 0 & 7 & 2.4 & 20 & 4.9 & 32 & 6.6 & 26.1
\end{tabular}


pit (280); fragments of rhizome were also recovered from a small number of the samples. Of note is the recovery of two apple pips from the fill of Pit 400 in Structure 1H; no other fruit pips or any pericarp remains have been recovered from the other excavated areas, and their presence probably indicates the exploitation of wild fruit resources.

\section{Distribution of plant remains}

There is a general low-level spread of cereal grain and weed seeds throughout a variety of features spread across the area, although it does appear that there is a slight increase in the quantity of plant remains recovered from Structure $1 \mathrm{H}$. No large concentrations of plant remains were uncovered to indicate any large-scale burning events. As with Areas B and C this sparse, almost uniform, spread of abraded material is probably the reworked and diluted remains of food burnt during daily activities and spread throughout many different deposits.

\subsection{Radiocarbon dates}

Nine radiocarbon date ranges were returned from this area and reflect MBA-LBA activity (Table 14; Illus 43). The only set of paired dates, those from Pit 360, were shown to be significantly different in a chi-squared test.

\subsection{Discussion}

\subsubsection{Phasing}

There was little evidence on which the phasing of the site could be based. There were no stratigraphic relations within the features with the exception of Linear Feature 003, which cut through an earlier pit (085), and which was itself cut by a later pit (005).

The radiocarbon dates suggest a period of activity from the MBA, with the cremation burial recovered from 149 (1208-998 cal BC; 95\% probability; UBA-13439), through to the LBA, with burnt cereal grains from Pit 142 dated to $895-804 \mathrm{cal} \mathrm{BC}$. The

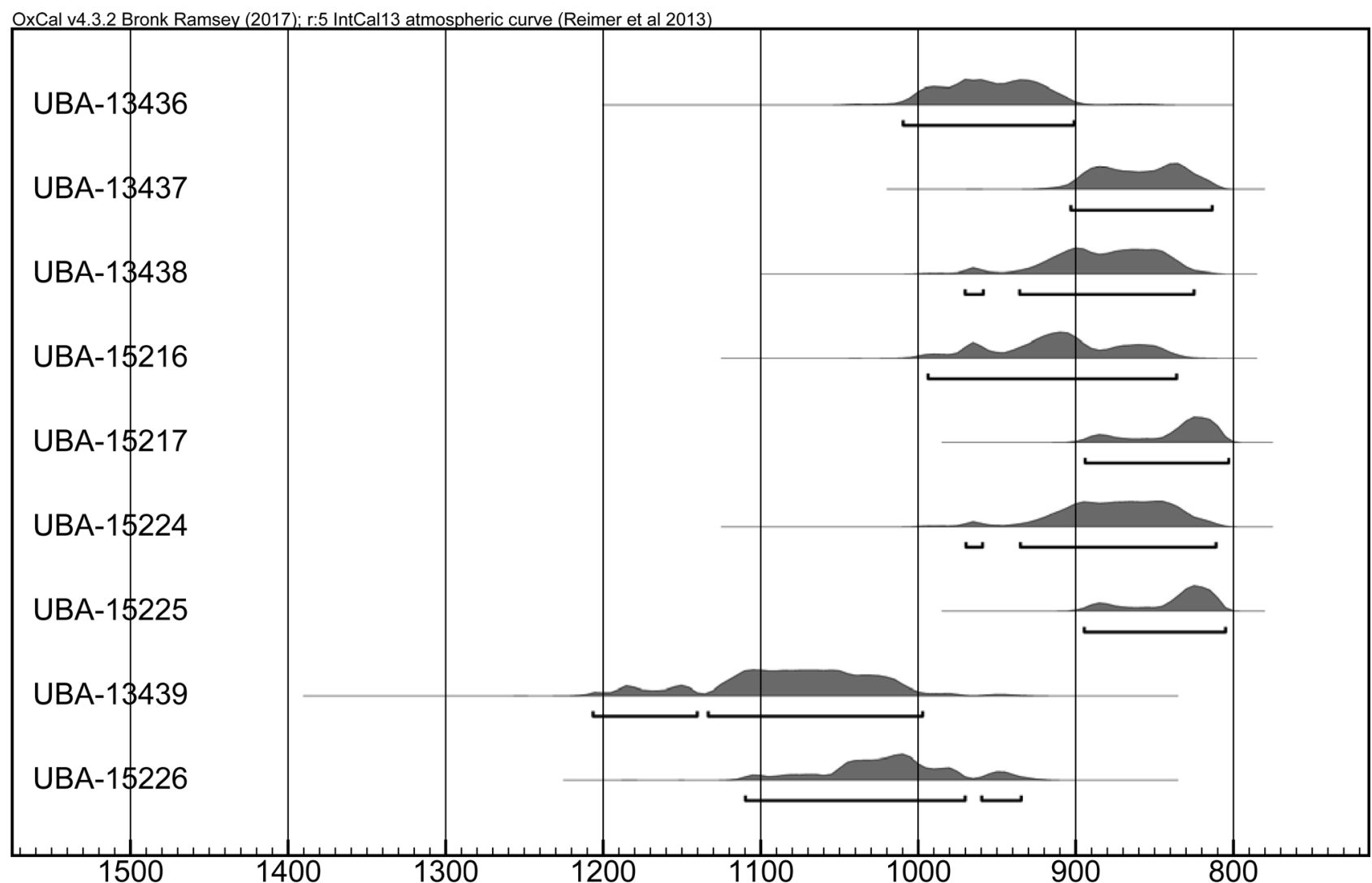

Calibrated date (calBC) 
Table 14 Radiocarbon dates, Area H. Calibration was conducted using OxCal v4.1.7, using the IntCal09 calibration curve

\begin{tabular}{|c|c|c|c|c|c|}
\hline Lab no. & Material & Context description & Date вр & $95 \%$ probability & $\begin{array}{l}\delta^{13} \mathrm{C} \\
\% 0\end{array}$ \\
\hline \multicolumn{6}{|l|}{ Structure $1 \mathrm{H}$} \\
\hline UBA-13436 & Hazel charcoal & Fill of internal Pit 360 & $2803 \pm 22$ & $1010-903$ вс & -29.1 \\
\hline UBA-13437 & Alder charcoal & Fill of internal Pit 360 & $2713 \pm 22$ & $904-815$ вс & -31.9 \\
\hline UBA-13438 & Hazel charcoal & Fill of internal Pit 288 & $2746 \pm 26$ & $972-825$ вс & -27.0 \\
\hline \multicolumn{6}{|l|}{ Area 1} \\
\hline UBA-15216 & Hazel charcoal & Pit 142 & $2768 \pm 26$ & $996-837$ вс & -27.2 \\
\hline UBA-15217 & Hazel charcoal & Pit 142 & $2685 \pm 21$ & $895-804$ вС & -27.3 \\
\hline \multicolumn{6}{|l|}{ Isolated pits } \\
\hline UBA-15224 & Barley indet. & Fill of Pit 329 & $2735 \pm 32$ & $971-813$ вс & -24.8 \\
\hline UBA-15225 & Barley indet. & Fill of Pit 329 & $2688 \pm 19$ & $895-806$ вс & -27.8 \\
\hline UBA-13439 & Human bone & Cremated Bone 149 & $2895 \pm 29$ & 1208-998 вс & -18.0 \\
\hline \multicolumn{6}{|l|}{ Linear feature } \\
\hline UBA-15226 & Hazel charcoal & Fill of Linear Feature 003 & $2856 \pm 21$ & $1114-936$ вс & -26.8 \\
\hline
\end{tabular}

cannel coal bangle fragment recovered from Pit 329, although not chronologically diagnostic, was found in association with cereal grains which returned dates of $971-813$ cal вс (95\% probability; UBA-15224) and $895-806$ cal вС (95\% probability; UBA-15225), suggesting the bangle was LBA in its origin.

\subsubsection{The cremation burials}

The remains of an adult cremation burial were recovered from Pit 149 just north of the linear feature (003). To the south of Linear Feature 003 burnt bone, possibly human, was recovered from Pit 076. There was no evidence of pyre debris marking the pyre site. For more detailed discussion see Section 11.4.

\subsubsection{Architectural features of the structures}

Very little can be said about Structure $1 \mathrm{H}$ except that it consisted of a partially surviving ring groove and a collection of pits thought to represent post holes, one of which (360) contained packing stones. The ring groove may have functioned as a foundation slot for the outer wall and the absence of ring ditches was in keeping with other LBA structures at Blackford such as Structure 1D.
The large pit (142) in Area 1 may have been the remains of a ring ditch. However, the dates returned were consistently of the LBA, and there were no other LBA structures at Blackford that had evidence of a ring ditch. It is possible that the feature was not a ring ditch, was an anomaly, or the dated material had become incorporated into an earlier feature. However, if it is a ring ditch it may represent a different use of the structure from the other LBA structures seen at Blackford.

\subsubsection{Finds distribution and taphonomy}

There is some evidence of a skewed deposition within the finds assemblage, with the majority coming from contexts with a proximal association with 003 (Illus 39). Both Pits 076 and 149 contained burnt bone and were close to the probable field boundary (003, 076 to the south and 149 to the north), and may represent acts of structured deposition. There is increasing evidence that critical points along field and enclosure boundaries are marked with special depositions such as concentrations of pottery or 'token cremations' (Brück 2001: 151), these token cremations usually being less than $50 \mathrm{~g}$, as were the human remains recovered in this area. The need 
for bulk sampling in order to retrieve these small amounts has been advocated by Guttman \& Last (2000: 155) and was the methodology employed during the excavations at Blackford. However, as a result of truncation much of the bone may have been lost and in actual fact the weight of the calcined bone making up the original cremation burial probably exceeded $50 \mathrm{~g}$.

Pottery was also collected from Pits 076 and 149 , as well as from other adjacent contexts on the south side of the boundary (034, 036 and 058$)$. To the north of the boundary, as well as the cremation (149), there was a shale bangle from Pit 329 and pottery from an adjacent pit (334). The rest of the retrieved pottery was from contexts that were some distance from 003: adjacent Pits 215 and 274 to the north-west of Structure $1 \mathrm{H}$, and isolated Pit 421 to the south-east of the structure.

\subsubsection{Economy}

Naked barley, emmer wheat and spelt are all represented within the area. Its diffuse distribution across the site, coupled with its abraded nature, indicates that this material derives from the daily processing and cooking activities involved with cereal grain. The recovery of apple pips suggests a degree of wild harvesting. Fragments of burnt animal bone were recovered. The recovery of an ovicaprid faecal pellet from the Late Bronze Age/ Early Iron Age (LBA/EIA) house Structure $1 \mathrm{~F}$ is supporting evidence that domesticated sheep/goat were being exploited.
It is not known whether the cannel coal bangle was manufactured at Blackford or not, but evidence of both the procurement of raw materials and the manufacture of jewellery was found in Areas B and E.

Prehistoric field boundaries are relatively common features of the Bronze Age in England (Yates 2007) and in north and west Europe generally (Harding 2000: 151), although they are not characteristic of Scotland. However, it appears that at Blackford one such boundary was recorded, Linear Feature 003.

If the area was divided by a fence then the fence was certainly not straight. Five pits that cut the feature may qualify as post holes, the sequence of construction being the same as that of the palisade in Area A, where a foundation slot was excavated, posts set within the cut, and then the cut backfilled. However, the irregularity in plan and section of Linear Feature 003, and its shallowness, does not offer support for a fence line. Alternatively, the land division may have been a hedge, with Pits 026, 060 and 062 having been formed by root boles. The hedge could have been formed from any thorny wild species, such as brambles (Harding 2000: 151). The putative hedge line was later cut by Post Hole 005, either because the hedge line had gone out of use and the post hole was entirely unrelated, or because it represents some form of augmentation to the hedge. Alternatively, the feature functioned as a drain, draining water downslope to the west and east. The pit then was latterly and coincidentally cut into the drain. 